Zanotti N.L. Maranhão F.L. and Aly, V.L.C. (2017). "Bottom-up Strategy for Lean Construction on Site Implementation.” In: LC3 2017 Volume II - Proceedings of the 25th Annual Conference of the International Group for Lean Construction (IGLC), Walsh, K., Sacks, R., Brilakis, I. (eds.), Heraklion, Greece, pp. 325-331. DOI: https://doi.org/10.24928/2017/0304

\title{
BOTTOM-UP STRATEGY FOR LEAN CONSTRUCTION ON SITE IMPLEMENTATION
}

\author{
Nero Lenotti Zanotti ${ }^{1}$, Flávio Leal Maranhão ${ }^{2}$, Vitor Levy Castex $\mathrm{Aly}^{3}$
}

\begin{abstract}
This paper shows a Lean Construction method being implemented with a bottom-up strategy, using spontaneous improvement as a tool for the implementation. To introduce the changes, all workers were trained on how to manage and identify the 8 types of waste, and presented to a simplified A3 thinking approach as a problem-solving technique.

The implementation occurred on a large infrastructure project with a total extension of $83 \mathrm{~km}$, using the construction of a water pipeline as an example, studying it for six months. To measure the results, the labor productivity rate and the average production-per-day rate were introduced as performance indicators, to analyse whether the implementation was successful or not.

By the end of the study, it was possible to observe a correlation between the number of improvements made, the labor productivity rate, and the average production-per-day rate, which implied a successful implementation of the lean philosophy.
\end{abstract}

Keywords: Lean construction, site implementation, kaizen, spontaneous improvement.

\section{INTRODUCTION}

There are many ways and different strategies to implement Lean Construction on construction companies. The most common ways of doing so are the top-down and the bottom-up strategies. Arbulu and Zabelle (2012) considered that the top-down method often pushed organizations to adopt a shallow and wide implementation approach, typically conceived and mandated by the leadership and without proper stakeholder engagement. Therefore, many difficulties for a successful implementation of the Lean Construction philosophy have been reported, as Berroir et al (2015) questions the sustainability of most actions done by company leaders for implementation, and as Jorgensen et al (2004) has observed, the cultural interpretations constituted a considerable impediment to process-oriented cooperation.

The main barrier to Lean Construction implementation is resistance by the middle management, supervisors and employees. Team resistance comprises more than $86 \%$ of the barriers to implementation, as shown in the Lean Enterprise Institute (2007) chart (Figure 1). This is the major problem that must be overcome for a successful lean transformation to occur.

Civil Engineer and M.Sc. Candidate, Escola Politecnica, Universidade de São Paulo, São Paulo, Brazil, nerozanotti@outlook.com

2 Professor, Escola Politécnica, Department of Construction Engineering, Universidade de São Paulo; Professor, Universidade São Judas Tadeu, São Paulo, Brazil, flavio.maranhao@poli.usp.br

3 Professor, Escola Politécnica, Department of Construction Engineering, Universidade de São Paulo;, São Paulo, Brazil, vitor.aly@usp.br 


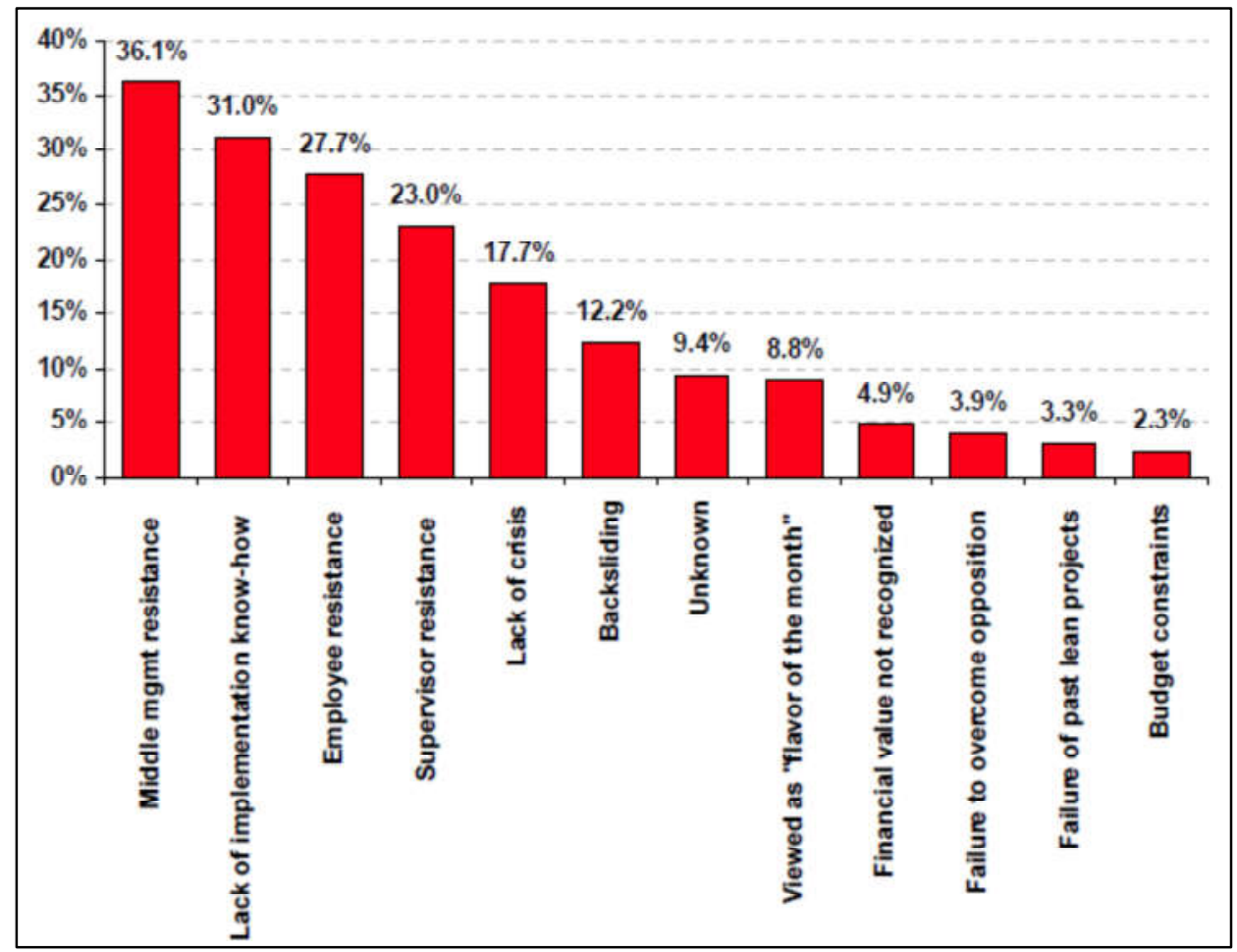

Figure 1: obstacles to lean implementation (Lean Enterprise Institute, 2007).

Reprinted with permission of Lean Enterprise Institute.

Meanwhile, Sarhan, S. and Fox, A. (2013) identified the top 3 barriers for Lean Construction implementation, in the following order:

- Lack of adequate lean awareness and understanding

- Lack of top management commitment

- Culture and human attitudinal issues

To address the implementation problems listed above, an alternative implementation method is the bottom-up strategy. According to Hook and Stehn (2008), this strategy implies that workers, by doing specific working routines, can implement a work culture, where the lean tools can improve how things are done traditionally. There are few published research studies that evaluate the on-site implementation of lean construction for workers, as Pichi and Granja (2014) did with lean principles; and Berroir et al (2015) did with added value analysis and 5S. However, no research was identified that focused on the training of employees such that they might be empowered to reduce or eliminate wastes in their own processes.

Motivated by the discussion above, this paper aims to evaluate an on-site implementation of lean construction using a bottom-up strategy, where the workers themselves improved their own processes. All data were collected by studying a large water pipeline construction site in Brazil.

\section{DESCRIBING THE PROJECT}

The project that was studied for this paper is a large water production system, with a flow rate of up to 6.4 cubic meters per second, made to supply a population of 500,000 . The system is consisted of: 
- A water intake facility

- A water treatment facility

- $83 \mathrm{~km}$ of water pipeline

- Another structures as water reservoirs and pumping stations

\subsection{Studied activity}

As previously stated, the scope of this paper is the construction of the pipeline, which has a diameter of $2.1 \mathrm{~m}$ and the trenches have 4 meters of depth. The initial estimated building cycle time is of one and a half day for every 7 meters of pipeline completed. The construction cycle is composed by the following activities:

- Soil Excavation

- Pipeline installation

- Welding

- Soil Backfill

The project had several crews doing the same job in different places in order to build it faster. The composition of the teams involved on the construction process for each of the activities is shown in Figure 2.

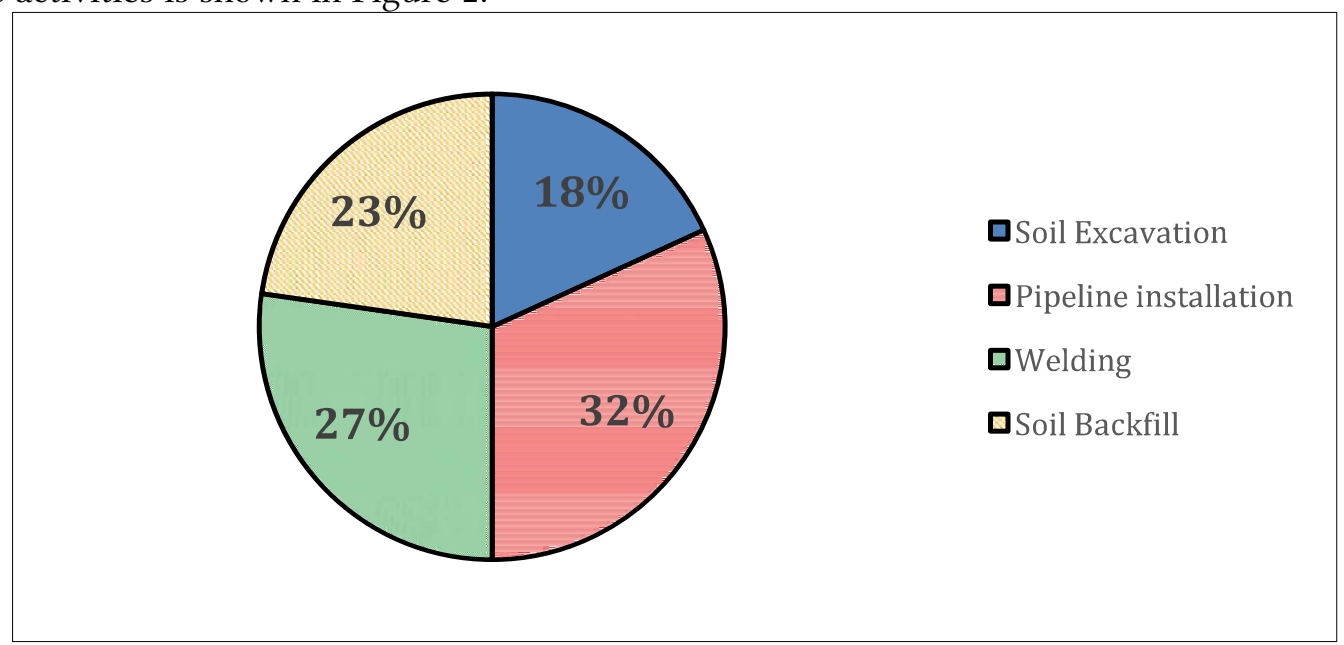

Figure 2: team composition for different activities of the water pipeline construction.

In this study, the water pipeline is considered as only one construction activity, that has the construction cycle mentioned above, and the product is always finished with the trench completely backfilled.

\section{STRUCTURING THE STRATEGY}

\subsection{Fundamentals and methodology}

As Womack and Jones (2013) describe, kaizen means continuous incremental improvement. They also say that a combination of both radical improvement (kaikaku) and continuous improvement (kaizen) can produce endless improvements.

This research focused on only continuous incremental improvements, or kaizen events. It began with a training phase in which all workers were trained. Then the 
improvements were captured using a kaizen form (Figure 3). Finally, all data collected were analyzed comparing the improvements and the labor productivity rate during the same period.

\subsection{Training phase}

The training provided to the workforce consisted in two specific topics of lean: waste reduction and problem solving.

As Liker (2004) mentioned, there are 8 types of wastes: overproduction, waiting, transportation, extra processing, inventory, excessive motion, defects and underutilized personnel. For each type of waste, it was showed to the workforce a contextualized example, for better understanding.

The other topic consisted of problem solving. To simplify the lesson, a reduced A3 thinking model for training was adopted so that the foremen and their crew could easily understand the concept.

The objective was to merge the two LC topics into one. Each time the workers found a waste, they were instructed to instinctively solve the problem as they had been trained, assisted by the engineers responsible for the task.

\subsection{Capturing the improvement}

As mentioned before, a simplified A3 thinking method was implemented, so that the foreman and his crew could identify different kinds of waste, and make improvements to overcome them. To register the actions taken on field, a proprietary form called "kaizen" (Figure 3) was developed. The kaizen form is divided in four different areas: waste or problem identification; waste or problem cause; solution or improvement implemented; and results obtained. It also has a checkbox, where the type of waste found can be marked.

All the data collect was compiled into a data base of improvement information so it could be analyzed.

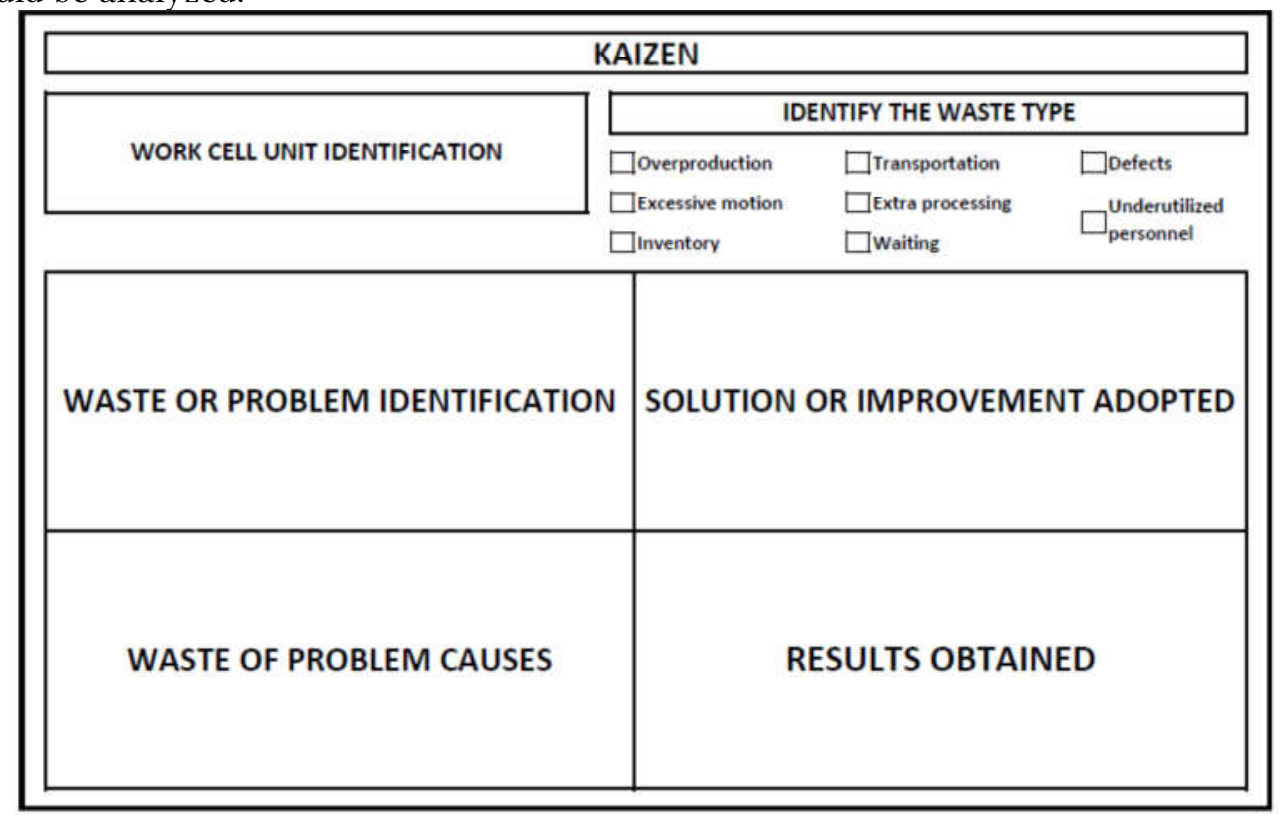

Figure 3: kaizen form. 
After the data was analyzed, the engineer responsible for the implementation of LC would visit the crew, to verify the improvements that were made, and to encourage the team to produce more kaizens forms by pointing out the results that were already obtained to promote continuous improvement.

\section{IMPROVEMENTS REFLECTING ON PRODUCTIVITY}

To measure the impact of the improvements, labor productivity rate and the average production-per-day rate were chosen as performance indicators, and assessed over a period of six months. Figure 4 shows the monthly productivity and the number of kaizen forms accumulated and analyzed for the water pipeline construction activity.

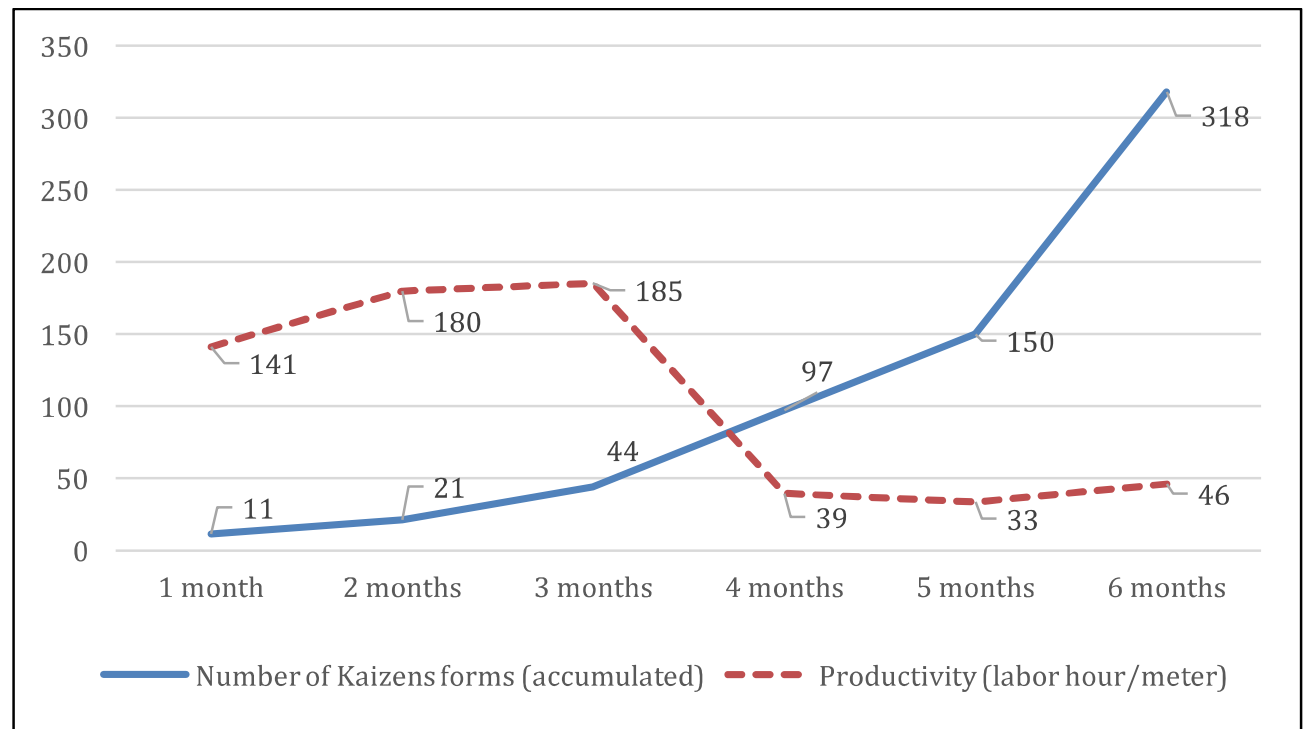

Figure 4: comparison of number of kaizen forms accumulated and labor productivity rate over time.

Figure 5 shows average production-per-day rate and the number of kaizens forms accumulated during the period. 


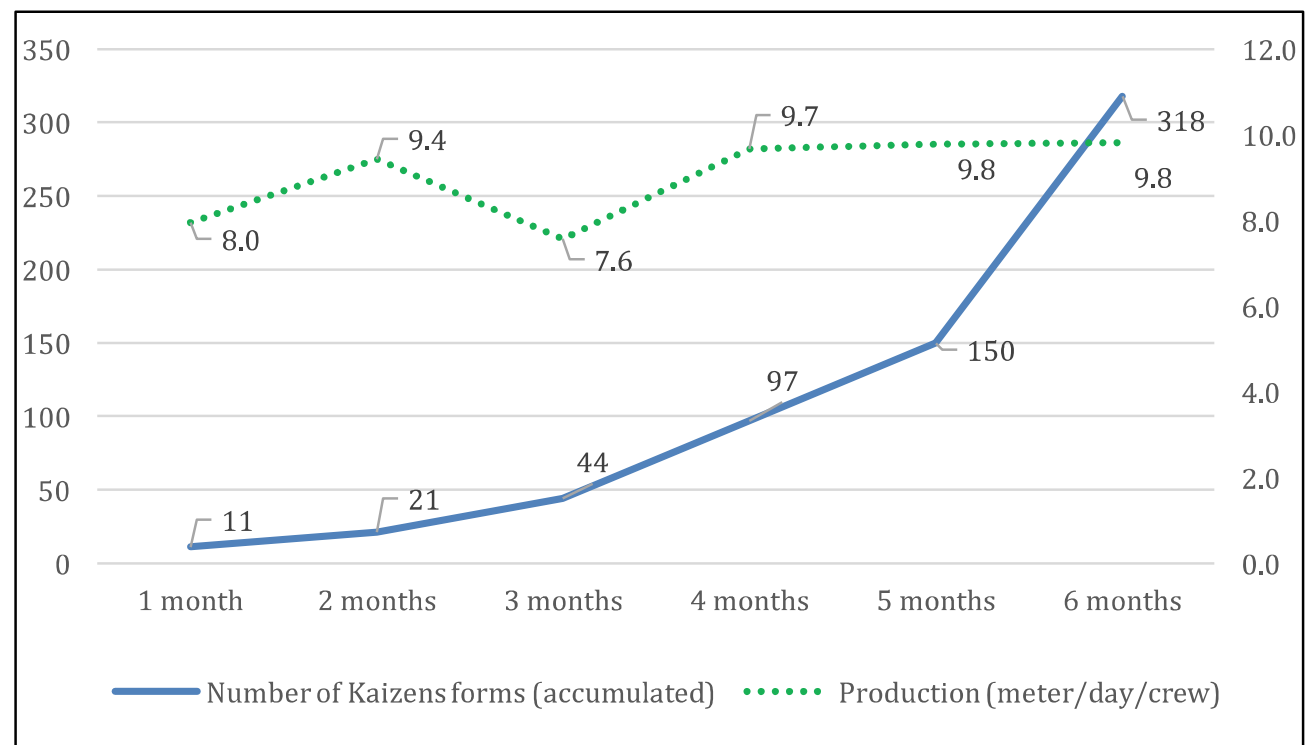

Figure 5: comparison of number of kaizens forms accumulated and average production-per-day rate.

Both figures 4 and 5 showed a correlation of the performance indicator and the number of kaizen forms accumulated during the period. The correlation on figure 4 means that over the increase of kaizens forms, less labor hours were necessary to do the task. So, the activity was becoming more productive. And the correlation on figure 5 means that more product was made in a single day over the increase of kaizen forms. Hence, these two facts were a result of a systematically waste reduction over time.

\section{CONCLUSIONS}

The bottom-up strategy for Lean Construction implementation on construction sites described on this paper is effective because it stimulates the engagement of the workers to make improvements on their own processes. This is made possible through training to enable them to find and eliminate wastes in their daily work.

Even though the labor productivity rate and the average production rate were chosen as the performance indicators for measuring the success of Lean Construction implementation on this case, it is expected that other performance indicators could also show a positive outcome, reflecting the improvements made by the kaizen forms, as shown on this paper. Systematically speaking, a reduction of waste on the construction process can also lead to an increase of quality and worker safety.

It was also observed that, as the number of kaizen grew, the effect it had on increasing the productivity and production rate would grow less, reaching a superior limit. This happened because the first improvements made had big impacts on performance, but as time went on, there was a tendency that the improvements would have a significantly smaller impact on performance, which meant that the work processes were close to their limit of improvement. Therefore, this study advocates radical change (kaikaku) followed by collective kaizen to promote a systematically continuous improvement.

To avoid that all the spontaneous improvement made could be somehow lost within time, it is suggested that a standardized manner of cataloguing what was made is created, 
to add the improvements made by the application of the kaizen forms into the working culture of the company. And to really achieve continuous improvement, further actions, taken from a top-down perspective, must be added to the bottom-up spontaneous improvement methods, so that the company can reach its peak efficiency on working routines on a faster way.

\section{REFERENCES}

Arbulu, R. and Zabelle, T. (2006). Implementing Lean in Construction: How to Succeed. Proceedings of IGLC, Santiago, Chile, pp.553-565.

Berroir, F., Harbouche, L. and Boton, C., 2015. Top down vs. Bottom up approaches regarding the implementation of lean construction through a French case study. In: Proc. 23rd Ann. Conf. of the Int'l. Group for Lean Construction. Perth, Australia, July 29-31, pp. 73-82, available at www.iglc.net

Lean Enterprise Institute, (2007). New Survey: Middle Managers Are Biggest Obstacle to Lean Enterprise. State of Lean Survey. p.4.

Jorgensen, B., Emmitt, S. and Bonke, S. (2004). Revealing Cultures and Sub-Cultures During the Implementation of Lean Construction. Proceedings IGLC, Helsingør, Denmark, p.13.

Höök, M. and Stehn, L., 2008. Lean principles in industrialized housing production: the need for a cultural change. Lean Construction Journal, 2, pp.20-33.

Picchi, F. and Granja, A. (2004). Construction Sites: Using Lean Principles to Seek Broader Implementations. Proceedings IGLC, Helsingør, Denmark, p.12.

Womack, J. and Jones, D. (2003). Lean thinking. 1st ed. New York: Free Press.

Liker, J. (2004). The Toyota way. 1st ed. New York: McGraw-Hill.

Sarhan, S. and Fox, A. (2013). Barriers to Implementing Lean Construction in the UK Construction Industry. The Built \& Human Environment Review, Volume 6, p.17. 